\title{
Growth and reproduction as a function of temperature and salinity in Clava multicornis (Cnidaria, Hydrozoa)
}

\author{
Otto Kinne and Gustav-Adolf Paffenhöfer \\ Biologische Anstalt Helgoland, Meeresstation, Helgoland
}

\begin{abstract}
KURZFASSUNG: Wachstum und Reproduktion als Funktion von Temperatur und Salzgehalt bei Clava multicornis (Cnidaria, Hydrozoa). Einzelpolypen eines Klons von C. multicornis FORSKÅL wurden schrittweise in 12 verschiedene Temperatur-Salzgehalts-Kombinationen überfuhht und - während sie zu neuen Kolonien heranwuchsen - das Längenwachstum ihrer Stolonen, die Geschwindigkeit ihrer asexuellen Vermehrung durch Knospung neuer Hydranthen sowie die Gonophorenausbildung (sexuelle Fortpflanzung) registriert. Die erhaltenen Daten sind unzureichend für eine detaillierte Analyse, gewähren jedoch interessante Einblicke in die Bedeutung der verschiedenen Temperatur- und Salzgehaltsbedingungen für Wachstum und Vermehrung. Die anfängliche, schrittweise Überführung in die Testmedien verursacht per se Leistungsunterschiede, deren Auswirkungen sich mindestens bis zu einem Alter von 39 Tagen verfolgen lassen. "Doubling times" stellen daher objektivere Kriterien dar als absolute Zuwachswerte. Die "doubling times" von Kolonien, welche länger als 20 Tage in den Testmedien gewachsen waren, zeigen eine Verringerung der Stolonenzuwachsrate mir steigender Temperatur $\left(12^{\circ}, 17^{\circ}, 22^{\circ} \mathrm{C}\right)$. Die Reihenfolge der fördernden Wirkung der einzelnen Salzgehaltsstufen ergibt sich zu $32 \%, 24 \%, 16 \%, 40 \% \mathrm{~S}$. Im Prinzip ähnliche Verhältnisse liegen hinsichtlich der asexuellen Vermehrungsrate vor. Bemessen an den getesteten Kriterien scheinen die Temperaturansprüche mit zunehmendem Koloniealter abzunehmen. Die errechneten "doubling times" sind wesentlich länger als bei Cordylophora; möglicherweise deutet dieser Unterschied auf inadäquate Kulturbedingungen (Fütterung, Wasserbewegung) hin.
\end{abstract}

\section{INTRODUCTION}

In a recent paper we have reported on the influence of different constant intensities of temperature and salinity on hydranth dimensions and digestion rate in the colonial hydroid Clava multicomis Forskål (Krnne \& Paffenhörer. 1965). The same material has now been examined with respect to growth rates of stolons, budding rates of new hydranths and the production of gonophores. Clava multicomis has proved to be a useful test animal for studying responses to altered environmental conditions.

All experiments were conducted in the Marine Station of the Biologische Anstalt Helgoland (island Helgoland, southern North Sea). 'They were executed by Mr. PAFFENHÖFER under the direction of the first named author. 


\section{MATERIAL AND METHODS}

The original colony from which the test individuals were obtained was collected in the "Helgoländer Felswatt", the shallow water area surrounding the island Helgoland. All cultures were started with single polyps (hydranths) cut off from one original colony (previously kept for weeks at $16^{\circ} \mathrm{C}$ and $32 \% 0 \mathrm{~S}$ ); they thus represented genetically identical material. On each side of the polyp basis, 3 to $4 \mathrm{~mm}$ stolon tubes were left in order to facilitate fast reattachment to the microscope slide provided as substratum. The test animals were offered 4-day-old larvae of the brine shrimp Artemia salina, which had been fed for 3 days on Dunaliella sp. (Order: Volvocales; Family: Polyblepharidaceae).

At intervals of 24 hours all colonies were fed once to full saturation (feeding time: 1 hour; light conditions during feeding: complete darkness; further details in KINNE \& PAFFENFörer 1965) and thereafter carefully cleaned and supplied with new water of the same temperature and salinity. In order to avoid undesired side effects due to sudden changes in temperature and salinity, the final test combinations of temperature and salinity were approached in small steps $\left(1^{\circ}\right.$ or $2^{\circ} \mathrm{C}$; less than $4 \% 00 \mathrm{~S}$ per day). Recordings of stolonate length began on the 9 th day after isolation of the single polyps.

The age of the test colonies referred to in this paper is defined as the period of time elapsing between the isolation of polyps and the recordings of growth and reproduction reported; reattachment of polyps occurred within 24 hours after the cutting off.

Counts of polyp numbers were restricted to hydranths having at least 2 tentacles. Thus the youngest stages, i. e. hydranth buds, were disregarded. All measurements were taken through a binocular microscope at a magnification of 12.5. Maintenance procedures were identical with those described in our earlier contribution, which should be consulted for further details on our methods (KINNE \& PAFFENHÖFER 1965).

\section{RESULTS}

Test individuals were exposed to three different constant levels of temperature, namely, $12^{\circ}, 17^{\circ}$ and $22^{\circ} \mathrm{C}$, and 4 different constant levels of salinity, namely, 16, 24, 32 and $40 \% \mathrm{~S}$. At $12^{\circ}$ and $17^{\circ} \mathrm{C}$ growth, asexual and sexual reproduction took place in all four salinities. At $22^{\circ} \mathrm{C}$ most colonies did not survive beyond 1 week in $16 \%$ or $40 \% \mathrm{~S}$. Consequently, no data on growth and reproduction are presented for these extreme factor combinations.

$$
\text { Growth of stolons }
$$

In the 12 temperature-salinity combinations employed, the diameters of the stolons did not change significantly. For simplicity, stolonate growth is therefore expressed only in terms of increase in length. In older colonies it became increasingly 


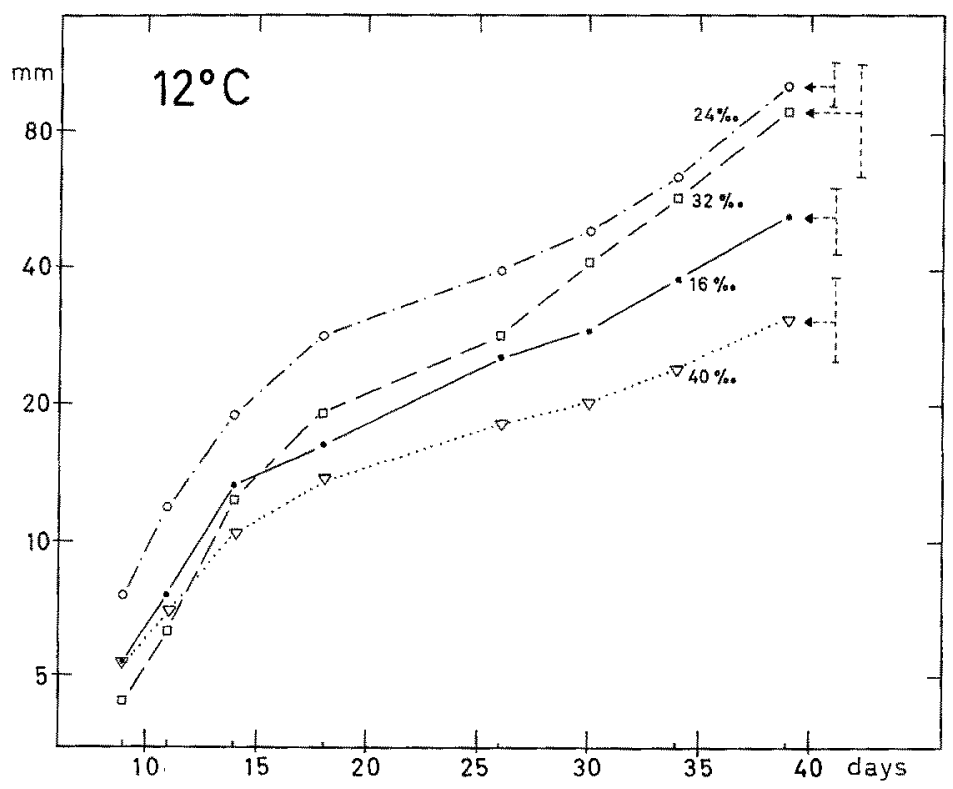

Fig. 1: Length increase in stolons of the hydroid Clava multicornis at $12^{\circ} \mathrm{C}$ in four different constant salinities. Each value represents the average of 8 measurements taken on different colonies. Dotted vertical lines indicate standard deviations of means in 39-day-old colonies.

\section{Semilogarithmic plot}

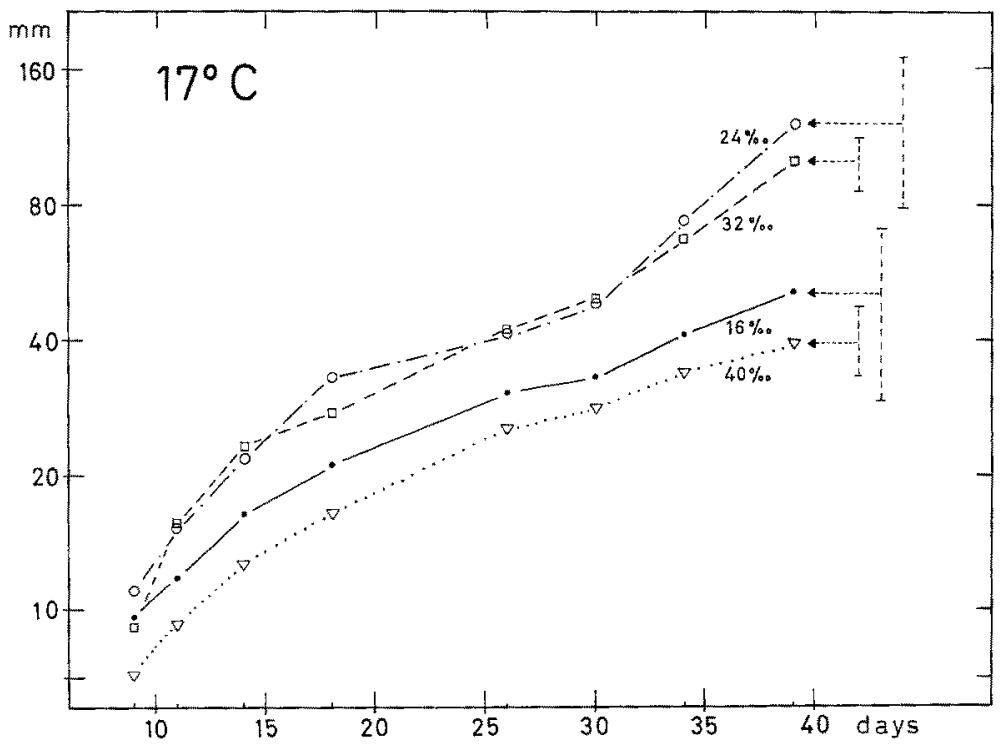

Fig. 2: Length increase in stolons of C. multicornis at $17^{\circ} \mathrm{C}$ as a function of salinity. For further details consult text to Figure 1 


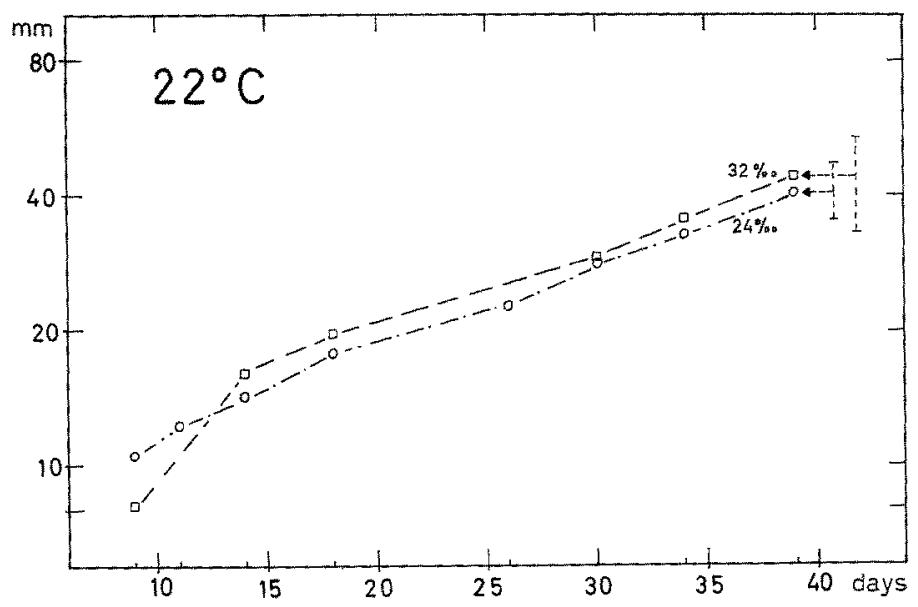

Fig. 3: Length increase in stolons of C. multicornis at $22^{\circ} \mathrm{C}$ (see text to Fig. 1)

difficult to measure the length increase of the stolon system, which gained rather quickly in complexity. Measurements were therefore terminated 39 days after the beginning of the experiments.

Following reattachment of the polyps cut off from the original colony on the glass slides provided, practically all test individuals began to grow noticeably within 24 hours. Up to an age of 39 days, stolons attained maximum lengths in all four salinities at $17^{\circ} \mathrm{C}$, followed by $12^{\circ} \mathrm{C}$ and then $22^{\circ} \mathrm{C}$ (Figs. $1,2,3$ ). While at $22^{\circ} \mathrm{C}$ stolonate growth was rather fast in the very first days, it later slowed down and continued at a fairly regular speed both in $24 \%$ and $32 \% 0 \mathrm{~S}$. The comparatively low growth rates at $22^{\circ} \mathrm{C}$ may be due to detrimental effects of the relatively high temperature; even more likely, they may be related to the food supply, i. e. to the length of time between subsequent feedings. As has been mentioned under material and methods, all colonies were fed only once a day. The high cost of maintenance and growth at $22^{\circ} \mathrm{C}$ seems to require a more continuous food supply for maximum performance.

At $12^{\circ}$ and $17^{\circ} \mathrm{C}$ the average stolonate length attained in the 39-day-old colonies decreases in the order $24 \%, 32 \%, 16 \%$ and $40 \% 00 \mathrm{~S}$, while at $22^{\circ} \mathrm{C}$ the final length reaches higher values in $32 \%$ than in $24 \% \mathrm{~S}$.

There is no doubt that the final stolonate length attained on the 39 th day bears a relationship to the growth achieved in the very first few days during which the newly cut-off hydranths were gradually transferred into the definite test combinations of temperature and salinity. In general, it may be assumed that the degree of a detrimental effect of the transfer itself increased with the difference between the original condition under which the primary colony had been kept $\left(16^{\circ} \mathrm{C}\right.$ and $\left.32 \% \mathrm{~S}\right)$ and the final test conditions. In order to eliminate the differences caused by such transfer effects as much as possible, growth rates have also been determined for the time span beginning on the 20 th day after initiation of experiments; these growth rates are 
recorded in Table 1; they are expressed in terms of the time span required to double the stolonate length attained on the 20 th day ("doubling times").

Table 1

Doubling times of stolon length (in full days) for the period beginning on the 20th day after initiation of experiments.

All data were obtained from curves presented in Figures 1 to 3

\begin{tabular}{|cccccc|}
\hline $\begin{array}{c}\text { Test } \\
\text { temperatures }\end{array}$ & $16 \% 0$ & $24 \% 0$ & $32 \% 0$ & $40 \% 0$ & Averages \\
\hline $12^{\circ} \mathrm{C}$ & 14 & 13 & 10 & 17 & 13.5 \\
$17^{0} \mathrm{C}$ & 16 & 15 & 13 & 17 & 15.3 \\
$22^{\circ} \mathrm{C}$ & - & 18 & 18 & - & 18.0 \\
\hline
\end{tabular}

Table 1 demonstrates that the doubling times obtained for the various salinity levels increase with increasing temperature. Such progressive reduction in growth rates in the order $12^{\circ}, 17^{\circ}, 22^{\circ} \mathrm{C}$ manifests itself also in the average values obtained for the test salinities at each temperature level. The stolonate growth rates obtained appear to indicate that the temperature requirements for maximum colony growth are higher in young colonies than in older ones. Furthermore, as has already been pointed out, they suggest that the feeding intervals may have been too long to yield maximum growth at the higher temperature levels. In regard to salinity, doubling times reach minimum values (indicating fastest growth) at $32 \%$, followed by $24 \%, 16 \%$ and $40 \% \mathrm{~S}$ (Table 1). At $22^{\circ} \mathrm{C}$ identical values were obtained both in $32 \%$ and $24 \% \mathrm{~S}$.

\section{Asexual reproduction}

Clava multicornis reproduces asexually by budding new polyps (hydranths). The rate of asexual reproduction can therefore conveniently be expressed in terms of increase in number of polyps per time unit. In order to facilitate a comparison with stolonate length data, hydranth numbers will first be considered for 39-day-old colonies. At this age the number of polyps per colony is maximal - with the exception of $16 \% \mathrm{~S}$ - at $17^{\circ} \mathrm{C}$. The other two temperature levels follow in the order $12^{\circ}$ and $22^{\circ} \mathrm{C}$ (Figs. $4,5,6,7$ ). The absolutely highest values were obtained at the combination of $17^{\circ} \mathrm{C}$ and $24 \% \mathrm{~S}$. Figure 7 demonstrates that, in principle, the rate of asexual reproduction is similarly affected by the temperature-salinity combinations offered as is stolonate length - with the obvious exception at $22^{\circ} \mathrm{C}$, where stolonate length increases from $24 \%$ to $32 \% \mathrm{~S}$, while the number of hydranths drops from an average of 7.2 to an average of 6.4 .

Calculations of doubling times for polyps numbers for the period beginning with the 20th day after initiation of experiments are presented in Table 2. The data obtained are not easy to interpret; they may be taken to indicate that doubling times for polyp numbers tend to decrease somewhat with increasing temperature (see averages obtained for test salinities at each temperature level). In other words - in contrast to stolonate 
length - the number of hydranths per colony may tend to increase somewhat with temperature, resulting in relatively more hydranths per length unit of stolons. At $12^{\circ} \mathrm{C}$ asexual reproduction is fastest in $24 \% \mathrm{~S}$, at $17^{0}$ and $22^{\circ} \mathrm{C}$, in $32 \% \mathrm{~S}$ (Table 2).

Table 2

Doubling times of polyp number per colony (in full days) beginning on the 20th day after initiation of experiments.

The data were obtained from the curves presented in Figures 4 to 6

\begin{tabular}{|cccccc|}
\hline $\begin{array}{c}\text { Test } \\
\text { temperatures }\end{array}$ & $16 \% 0$ & $24 \%$ & $32 \%$ & $40 \%$ & Averages \\
\hline $12^{\circ} \mathrm{C}$ & 31 & 19 & 24 & 20 & 23.5 \\
$17^{\circ} \mathrm{C}$ & 27 & 17 & 16 & 27 & 21.7 \\
$22^{\circ}$ & - & 20 & 16 & - & 18.0 \\
\hline
\end{tabular}

Colonies maintained beyond 39 days show that at an age of 56 days most polyps are carried at $12^{\circ} \mathrm{C}$ (exception: $24 \% \mathrm{~S}$ ), fewer at $17^{\circ} \mathrm{C}$ and still fewer at $22^{\circ} \mathrm{C}$ (Table 3). In a comparison with the results obtained on younger colonies, the data of Table 3 appear to indicate again that the temperature optimum for colony growth decreases with increasing colony age. In regard to salinity the order of hydranth number increase reads $24 \%>32 \%>16 \%>40 \% \mathrm{~S}$, this order being identical with the one obtained for stolonate length in 39-day-old colonies.

Table 3

Average number of polyps per 56-day-old C. multicornis colony. Averages of 6 to 8 colonies in each case

\begin{tabular}{|ccccc|}
\hline $\begin{array}{c}\text { Test } \\
\text { temperatures }\end{array}$ & $16 \% 0$ & $24 \%$ & $32 \% 0$ & $40 \% 0$ \\
\hline $12^{\circ} \mathrm{C}$ & 13.9 & 28.2 & 26.8 & 12.2 \\
$17^{\circ} \mathrm{C}$ & 11.3 & 36.0 & 24.2 & 10.8 \\
$22^{\circ} \mathrm{C}$ & - & 14.2 & 12.0 & - \\
\hline
\end{tabular}

During the initial period of transfer into the final test media, the rate of asexual reproduction seems to have been stimulated by a reduction in salinity. Thus at $12^{0}$ and $17^{\circ} \mathrm{C}$ the $16 \% 0 \mathrm{~S}$ colonies produce new hydranths at the fastest rate up to an age of 10 to 12 days (Figs. 4 and 5), and at $22^{\circ} \mathrm{C}$ the $24 \% \mathrm{~S}$ colonies bud considerably more hydranths during the first weeks than the $32 \%$ ones (Fig. 6).

\section{Sexual reproduction}

Clava multicornis reproduces sexually via the formation of sessile gonophores of the cryptomedusoid type, which protrude from the hydranth body just below the insertion points of the lowest tentacles. Both at $12^{\circ}$ and $17^{\circ} \mathrm{C}$ gonophores were formed 


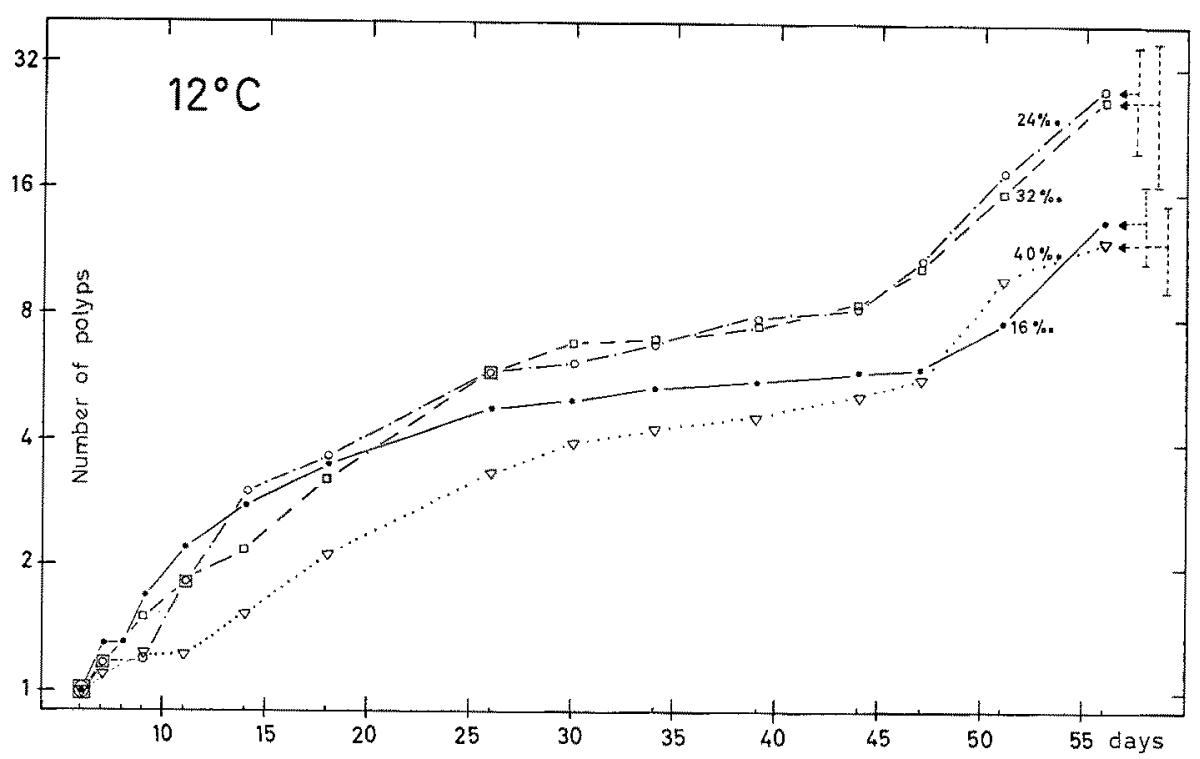

Fig. 4: Polyp numbers per colony of C. multicornis exposed to $12^{\circ} \mathrm{C}$ and four different constant salinities. Each value represents the average of 7 measurements taken on different colonies. Dotted lines indicate standard deviations of means in 56-day-old colonies.

Semilogarithmic plot

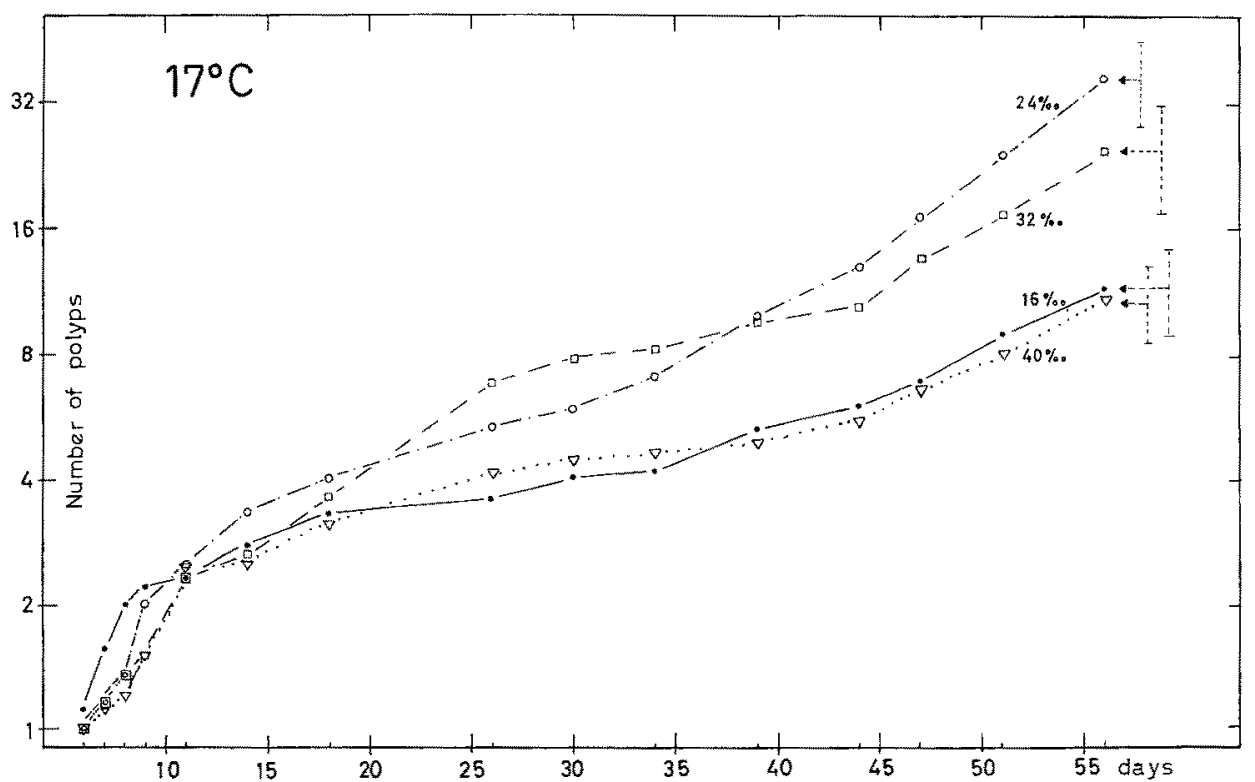

Fig. 5: Polyp numbers in C. multicornis colonies exposed to $17^{\circ} \mathrm{C}$; for further details consult text to Figure 4 


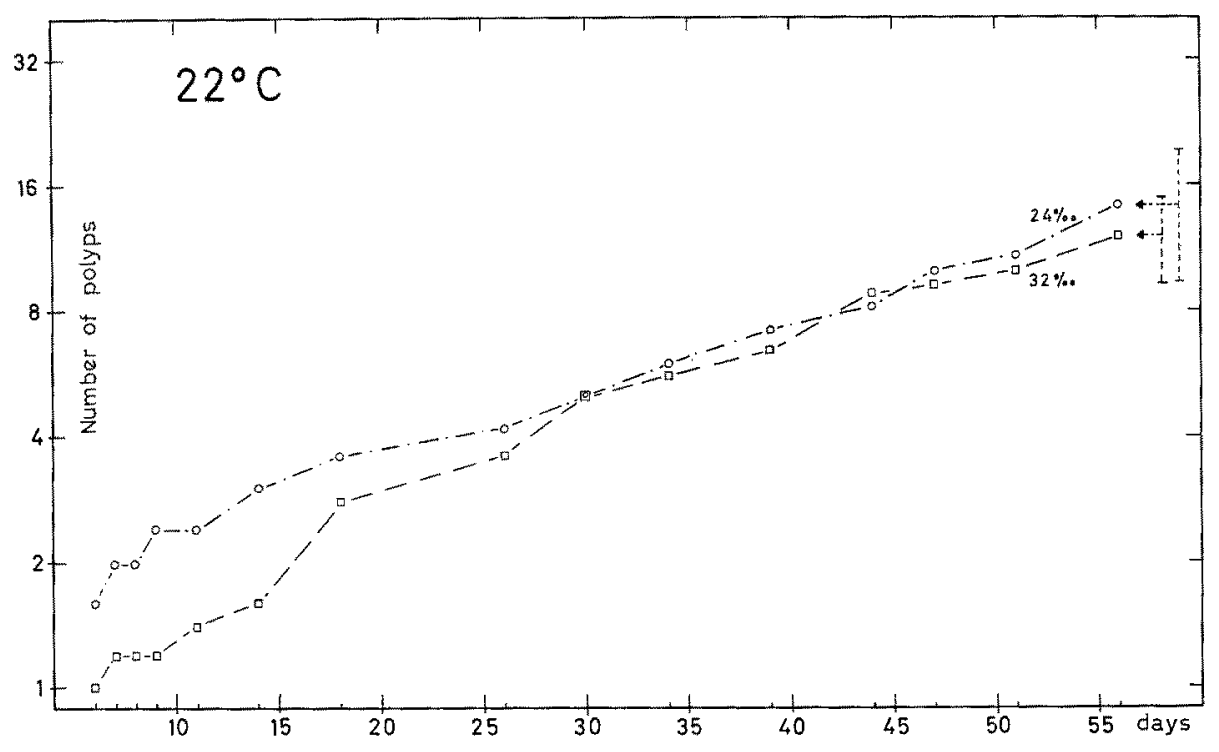

Fig. 6: Polyp numbers in C. multicornis colonies exposed to $22^{\circ} \mathrm{C}$ (see text to Fig. 4)

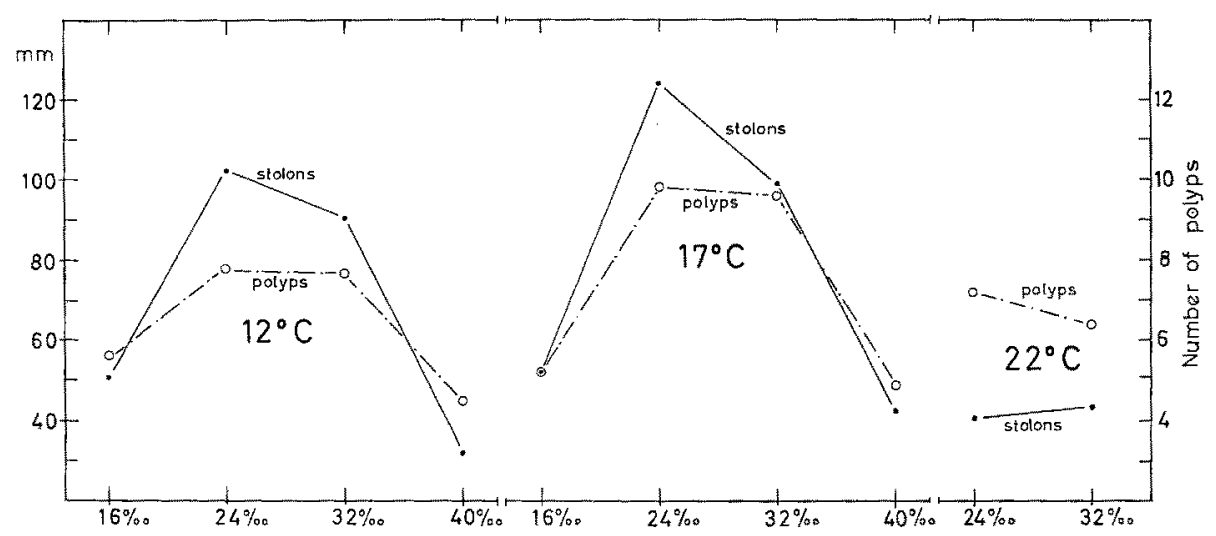

Fig. 7: Comparison of increase in stolon length (left scale) and polyp numbers (right scale) in 39-day-old C. multicornis colonies exposed to different combinations of temperature and salinity. Averages of 7 to 8 measurements in each case

in all four salinities. At $22^{\circ} \mathrm{C}$, however, no sexual reproduction was observed. Temperature and salinity ranges are narrower for sexual than for asexual reproduction.

Additional experiments in which the colonies were hand-fed demonstrate that gonophore production depends on the amount of food offered. Number and size of gonophores tend to increase with increasing food supply. Moreover, older Artemia larvae seem to represent a better food source, i. e. allow faster and more intensive gonophore production, than 1 or 2 -day-old ones. 


\section{DISCUSSION}

While insufficient for a detailed analysis, the data obtained in the present study provide interesting insights into the variability of growth and reproduction of Clava multicornis caused by different intensities of temperature and salinity. They are intimately related to our previous study reporting effects of temperature and salinity on the hydranth structure and digestion rate of C. multicornis (KINNE \& PAFFenHÖFER 1965).

Even though hydranth lengths (according to KINNE \& PAFFEnHören 1965), as well as stolonate growth rates and polyp numbers of mature colonies, tend to decrease with increasing temperature $\left(12^{\circ}, 17^{\circ}, 22^{\circ} \mathrm{C}\right)$, the relationship between hydranth structure and colonial growth rate is still somewhat obscure. In a closely related brackish-water living hydroid, Cordylophora caspia (syn.: C. lacustris), however, it has been possible to demonstrate a positive quantitative relation between surface area of hydranths and growth rates of colonies (KINNE 1958, p. 475/6). The rather beneficial effects of $32 \% \mathrm{~S}$ on growth in C. multicornis may be related to maximum digestion rates at that salinity level (KINNE \& PAFfenhöfeR 1965).

From the comparison of the data obtained in colonies of different ages (a few days, 39 days, 56 days old), several conclusions may be drawn: (1) It appears that temperature requirements for maximum colony increase are reduced as the colony grows older. (2) One feeding period per day seems insufficient for maximum performance at the higher temperature levels, especially at $22^{\circ} \mathrm{C}$. (3) The different degrees of environmental stress endured during the transfer period (first few days during which the newly cut-off polyps were stepwise exposed to the definite test media) have affected the initial growth rates; the resulting differences in "start-size" are reflected in final stolon length and hydranth number even up to the 39th day. More objective criteria for the assessment of rates of growth and asexual reproduction are therefore the "doubling times", that is, the number of days within which stolonate length or number of hydranths taken on the 20th day after initiation of experiments have doubled.

Doubling times have been read from the curves presented in Figures 1 to 6 . They demonstrate that the amount of increase in stolon length is progressively reduced (prolonged doubling times) with increasing temperature (Table 1). In regard to salinity, stolonate doubling times indicate fastest length increase in $32 \%$, followed by $24 \%, 16 \%$ and $40 \% \mathrm{~S}$. Compared with stolon length, doubling times of polyp number per colony (Table 2) exhibit less obvious relationships to temperature. A definite trend, however, is exhibited by colonies maintained up to an age of 56 days. In these mature colonies hydranth number per colony reaches its maximum at $12^{\circ} \mathrm{C}$; fewer hydranths are carried at $17^{\circ}$ and the fewest at $22^{\circ} \mathrm{C}$; the respective salinity sequence reads: $24 \%, 32 \%, 16 \%, 40 \% \mathrm{~S}$. Thus, ultimately, rates of increase in stolon length and polyp number per colony obtained at the different temperaturesalinity combinations are similar.

In Clava multicomis doubling times for stolon length range between 10 and 18 days, for polyp number, between 16 and 31 days (Tables 1,2). These periods are very long compared to those found for the brackish water living Cordylophora. In 
this species KINNE (1956, 1958) found doubling times for length increase in stolons plus hydrocauli (stems) and for hydranth number to be about 4 to 5 days, and Fulton (1962), about 3 days. The long doubling times found for C. multicornis may be indicative of suboptimal culture conditions. All cultures were kept in non-moving media. Water movement may increase rates of growth and reproduction; experiments putting this hypothesis to critical test are presently being carried out.

FulToN (1960), who was interested in developing a rigidly standardized culture method yielding maximum growth rates rather than in ecological considerations, described a new chemically well defined culture medium for Cordylopbora. Using his new medium FulToN $(1962,1963)$ was able to produce important information on growth rates and developmental patterns of this brackish water hydroid. According to his experiments (1963) stolons, uprights and branches grow - under identical culture conditions - at constant rates once they reach a certain length; their relative growth rates, however, are different: stolons grow at about twice the rate of uprights, and uprights grow more rapidly than branches.

The increase of stolon length and hydranth number per colony of Clava multicornis is, in principle, exponential. This is evident from the semilogarithmic plots of Figures 1 to 6 . Under his strictly standardized conditions Fulton (1962) produced clear evidence for exponential growth in Cordylophora; he has further shown that Cordylopbora achieves exponential colony growth by addition of secondary stolons at appropriate time intervals (1963).

Most of our curves illustrating average as well as individual rates of stolon growth and asexual reproduction exhibit more or less regular undulations. Such undulations are often even more obvious in single colonies. Similar, if sometimes less pronounced, regular undulations can also be detected in FultoN's curves depicting growth of Cordylophora colonies. Since Fulton's data were obtained under very uniform external conditions, the undulations seem to be indicative of endogenous growth rhythms.

\section{SUMMARY}

1. Rates of growth (length increase of stolons) and of asexual reproduction (increase in number of polyps) were determined in secondary Clava multicornis colonies of a clone exposed to 12 different combinations of water temperature and salinity $\left(12^{\circ}, 17^{0}, 22^{\circ} \mathrm{C} ; 16 \%, 24 \%, 32 \%, 40 \% \mathrm{~S}\right)$. Sexual reproduction (via gonophores) has been observed only at $12^{\circ}$ and $17^{\circ} \mathrm{C}$; temperature and salinity ranges are narrower for sexual than for asexual reproduction.

2. The data obtained are insufficient for a detailed analysis; they provide, however, interesting insights into the variability of growth and reproduction of C. multicornis caused by different intensities of temperature and salinity.

3. It appears that temperature requirements for maximum colony increase are reduced as the colony grows older.

4. One feeding period per 24 hours seems insufficient for maximum growth and reproduction at the higher temperature levels, especially at $22^{\circ} \mathrm{C}$. 
5. The different degrees of environmental stress endured during the initial period of transfer into the test combinations of temperature and salinity have affected the resulting colony size at least up to an age of 39 days. More appropriate criteria for assessment of rates of growth and reproduction are therefore the doubling times (number of days within which stolon length and polyp numbers taken 20 days after initiation of experiments have doubled).

6. On the basis of doubling time values, increase in stolon length is progressively reduced with increasing water temperature $\left(12^{\circ}, 17^{\circ}, 22^{\circ} \mathrm{C}\right)$. At $12^{\circ}$ and $17^{\circ} \mathrm{C}$ stolons grow fastest in $32 \%$, followed by $24 \%, 16 \%$ and $40 \% 00 \mathrm{~S}$; at $22^{\circ} \mathrm{C}$ stolon growth rates are identical in $32 \%$ and $24 \% \mathrm{~S}$.

7. Doubling times of polyp numbers per colony show a less obvious trend. In 56-day-old colonies, however, stolon length and polyp number are modified to similar degrees by the various temperatures and salinities offered. The sequence of temperatures causing fastest increase in polyp number is $12^{\circ}>17^{\circ}>22^{\circ} \mathrm{C}$; the respective sequence of salinities reads: $24 \%, 32 \%, 16 \%, 40 \% \mathrm{~S}$.

8. Stolon length and polyp number per colony increase exponentially; most curves obtained exhibit undulations indicating endogenous grow th rhythms.

9. During the initial period of transfer into the final test media, asexual reproduction via budding seems to have been stimulated by a reduction in salinity.

10. The doubling times obtained for C. multicornis are considerably longer than those found for Cordylophora caspia and indicate that our culture conditions may have been suboptimal.

\section{ACKNOWLEDGMENTS}

This study was supported financially by the Deutsche Forschungsgemeinschaft (Grant Ki 41/9). Miss F. W. CROUSE and Mr. J. Marschall helped to prepare the manuscript and figures. We gratefully acknowledge this assistance.

\section{LITERATURE CITED}

Fulton, C., 1960. Culture of a colonial hydroid under controlled conditions. Science, N. Y. $132,473-474$.

- 1962. Environmental factors influencing growth of Cordylophora. J. exp. Zool. 151, 61-78.

- 1963. The development of a hydroid colony. Devl Biol. 6, 333-369.

KINNE, O., 1956. Uber den Einfluß des Salzgehaltes und der Temperatur auf Wachstum, Form und Vermehrung bei dem Hydroidpolypen Cordylophora caspia (Pallas), Athecata, Clavidae. Zool. Jb. (Allg. Zool. Pbysiol. Tiere) 66, 565-638.

- 1958. Ober die Reaktion erbgleichen Coelenteratengewebes auf verschiedene Salzgehaltsund Temperaturbedingungen. Zool. Jb. (Allg. Zool. Physiol. Tiere) 67, 407-486.

- \& PAFFENHÖFER, G.-A., 1965. Hydranth structure and digestion rate as a function of temperature and salinity in Clava multiconis. Helgolander wiss. Meereswnters, 12, 329-341. 